\title{
Temporal and Spatial Development of Cercospora Leaf Spot of Faba Bean Influenced by In Situ Inoculum
}

R. B. E. Kimber, South Australian Research and Development Institute (SARDI), Plant Health \& Biosecurity, Adelaide, SA 5001, Australia; and School of Agriculture, Food \& Wine, University of Adelaide, Waite Campus, SA, Australia; J. G. Paull, and E. S. Scott, School of Agriculture, Food \& Wine, University of Adelaide, Australia; and C. B. Dyson, and J. A. Davidson, SARDI, Plant Health \& Biosecurity, Adelaide

\begin{abstract}
Kimber, R. B. E., Paull, J. G., Scott, E. S., Dyson, C. B., and Davidson, J. A. 2016. Temporal and spatial development of Cercospora leaf spot of faba bean influenced by in situ inoculum. Plant Dis. 100:1823-1830.

The temporal and spatial dynamics of Cercospora leaf spot on susceptible and resistant lines of faba bean grown in or at defined distances from soil with residues infested by Cercospora zonata were examined in South Australia in 2005 and 2006. The disease was first observed on susceptible seedlings 49 days after sowing (DAS) in soil that had been sown with faba bean every 3 years since 1997 (positive soil zone for C. zonata) but was delayed by 1 week in adjacent soil ( 0 to $16 \mathrm{~m}$ away) with no history of cultivation of faba bean (negative soil zone). The incidence of diseased seedlings from 49 to 63 DAS showed a gradient from 4 to $16 \mathrm{~m}$ from the infested soil and was significantly greater for susceptible plants grown in the positive versus negative soil zones in field trials conducted in 2005 and 2006 (92 versus 30\% in 2005, $\chi^{2}{ }_{1}=32.2, P<0.001 ; 98$ versus $55 \%$ in $\left.2006, \chi^{2}{ }_{1}=12.1, P<0.001\right)$. The incidence of Cercospora leaf spot on the resistant line $1322 / 2$ was significantly less $\left(\chi^{2}{ }_{6}=171.7\right.$; $P<0.001)$ than on the susceptible line 'Farah' at that time in both years, with fewer than $5 \%$ of the seedlings showing the disease. However, a gradient was shown at 70 to 84 DAS, where disease incidence was significantly greater on line $1322 / 2$ in the positive soil zone than on plants in the negative soil zone in both years (62 and $18 \%$, respectively, with $\chi^{2}{ }_{1}=27.9, P<0.001$ in the 2005 trial; and 47 and $6 \%$, respectively, with $\chi^{2}{ }_{1}=33.3, P<0.001$ in the 2006 trial). At peak disease severity on Farah, Cercospora leaf spot mean leaf area diseased (\%LAD) was

severe $(85 \pm 4.3 \%)$ on leaves of the three nodes closest to the soil surface, and much less severe $(1 \pm 0.6 \%)$ in the upper canopy. Defoliation combined with \%LAD was used to describe the loss of photosynthetic leaf area (\%LPLA) in both cultivars, on both soil zones, in each year. Nonlinear regression analyses using a logistic model described disease development over time on susceptible plants grown in infested soil (e.g., for $+12-\mathrm{m}$ blocks within infested soil, $y=2.66+46.08 /[1+\exp (-0.23 \times[X-$ $40.92])]$ in 2005 and $y=0.49+5.02 /[1+\exp (-0.14 \times[X-28.30])]$ in 2006, where $X=$ DAS and $y=\%$ LPLA, with both regressions significant at $P<0.001$ ), whereas an exponential model (e.g., for $-12-\mathrm{m}$ blocks from infested soil, $y=0.23+0.77 \times 1.04^{X}$ in 2005 and $y=0.44+$ $0.56 \times 1.04^{X}$ in 2006 , both at $P<0.001$ ) best described disease gradients with increasing distance from the inoculum source. Paired $t$ tests of \%LPLA at 77 and 98 DAS showed significant differences in disease severity in the positive versus negative soil zones and a steep gradient in \%LPLA from 0 to $4 \mathrm{~m}$ from the inoculum source. The role of infested faba bean residue in survival of $C$. zonata over time was also examined using a pot-bioassay and in situ field assay. When residues were removed from the soil surface or depleted rapidly by animal grazing, the amount of $C$. zonata inoculum in the soil was significantly less $(P<0.001)$ than for soil with residue remaining on the soil surface. $C$. zonata survived in soil and remained infective for at least 30 months after harvest of an infected faba bean crop.
\end{abstract}

Cercospora leaf spot, caused by Cercospora zonata, is a fungal disease that affects faba bean (Vicia faba L.) in most countries where the crop is cultivated (Williams 1987). However, the disease is not considered a major threat to faba bean production and, consequently, few researchers have examined the life cycle of $C$. zonata in faba bean production (Woodward 1932; Yu 1947). C. zonata is reported to have a limited host range, confined to Vicia spp. such as $V$. faba, $V$. narbonensis (narbon bean), and V. sativa (vetch) (Williams 1987). There is evidence that, in the Mediterranean-type environments of southern Australia, Cercospora leaf spot has increased in prevalence and severity in commercial crops since 2004 (Kimber and Paull 2011). The reasons for this increase are not obvious. In the absence of cultivars with resistance to Cercospora leaf spot (Kimber and Paull 2011), disease management is dependent on strategies based on knowledge of pathogen survival, dissemination, and development. However, the epidemiology of Cercospora leaf spot on faba bean has remained poorly understood. This study was intended to investigate some of the gaps in knowledge of survival and spread of the pathogen in faba bean production in southern Australia.

Conidia of most Cercospora spp. are borne on erect conidiophores formed as fascicles above the leaf surface, which protrude into the air

Corresponding author: R. B. E. Kimber; E-mail: rohan.kimber@sa.gov.au

Accepted for publication 11 April 2016.

http://dx.doi.org/10.1094/PDIS-12-14-1264-RE

(C) 2016 The American Phytopathological Society
(Meredith 1973). The conidia are detached passively and are dispersed by wind or rain-splash (Lapaire and Dunkle 2003; Williams 1987). C. zonata is presumed to persist as fascicles of conidiophores or as dormant stromatic mycelium in crop residue remaining on the soil surface (Walker 1952; Yu 1947). The principal agents for dispersal of conidia from infested residue on the soil surface are likely to be wind and rain, which influence spatial patterns of disease distribution (de Nazareno et al. 1993; Vereijssen at al. 2006; Ward et al. 1999). Reports on dispersal of $C$. beticola, the causal agent of Cercospora leaf spot on sugar beet, show that, when wind is the principal dispersal agent, spatial patterns are less distinct than when rain-splash is involved, because dissemination by wind can occur over greater distances from infected crops (Khan et al. 2008; Lawrence and Meredith 1970). Dispersal of conidia by rain-splash, in contrast, resulted in decreasing incidence of Cercospora leaf spot over short distances, with infection from infested debris at the soil surface occurring first on the lower leaves and wind playing a secondary role in inoculum dispersal (McKay and Pool 1918; Vereijssen at al. 2006; Windels et al. 1998). Such information is required for Cercospora leaf spot on faba bean to elucidate the factors that may influence disease incidence and spread in commercial crops in southern Australia, and improve management strategies of the disease.

Likewise, survival of $C$. zonata has not been studied in much detail. Preliminary field studies in China demonstrated that the pathogen could survive for 8 months on diseased leaf material after shallow burial in soil ( $\mathrm{Yu}$ 1947). The current recommendation for Australian growers is to maintain an approximately 4-year rotation between faba bean crops within a field, by which time infested residues with survival structures of other major pathogens (e.g., Ascochyta 
fabae and Botrytis fabae) typically have decomposed and no longer represent a significant source of inoculum based on studies in other countries (Dyke and Prew 1983; Wallen and Galway 1977). Although the persistence of Cercospora leaf spot inoculum on faba bean crop residues is not known, anecdotal evidence suggests that the pathogen may remain viable for a period of 3 to 4 years (K. Rohan, personal observation). Survival of other Cercospora spp. on infested residues varied from several months to several years when residues were retained on the soil surface but decreased more rapidly when residues were buried (Cooperman et al. 1986; de Nazareno et al. 1992; Kilpatrick 1956; Nagel 1938; Payne and Waldron 1983). Consequently, cultural practices to reduce persistence of residues, such as burial by tilling, are

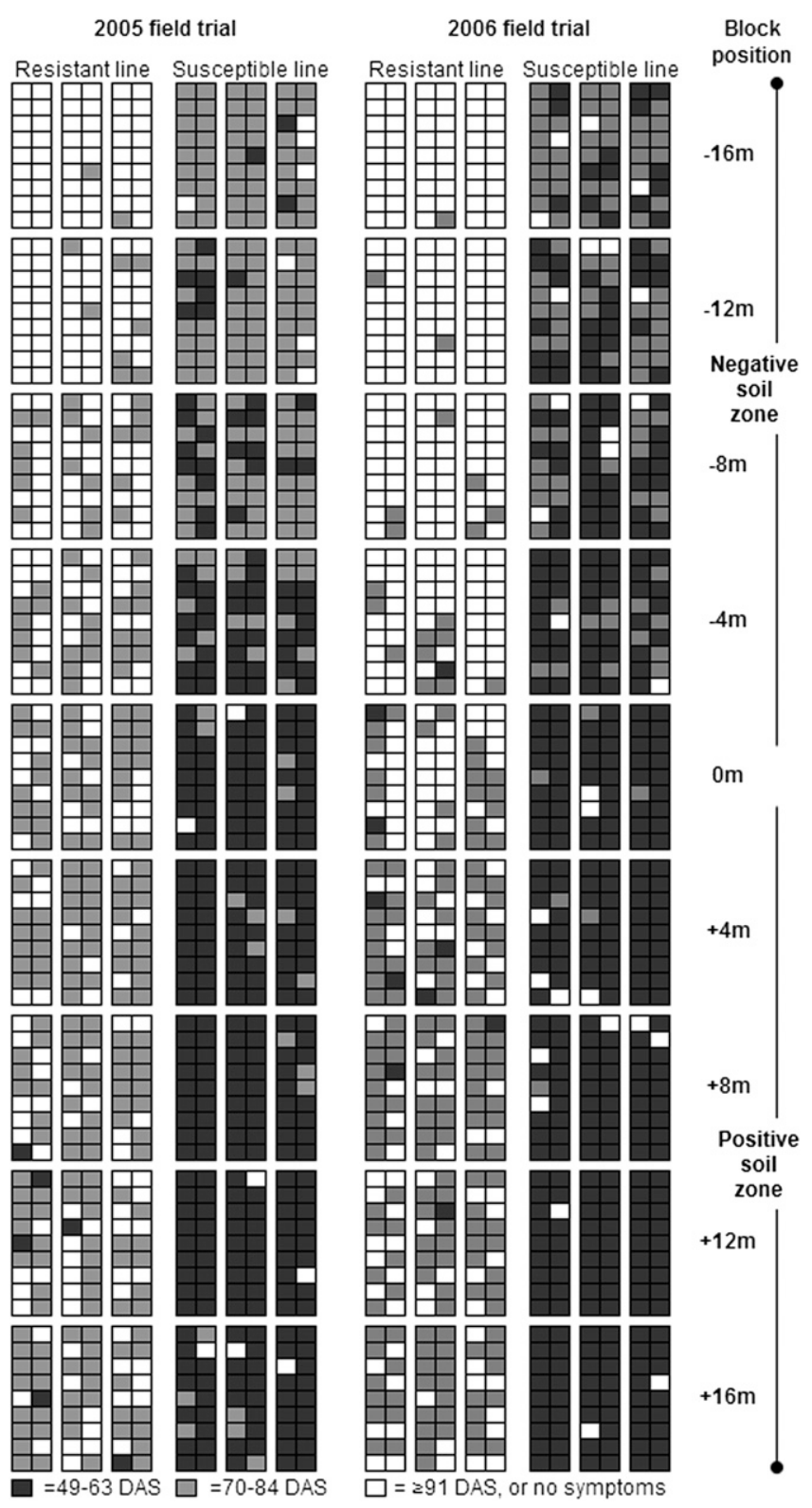

Fig. 1. Temporal and spatial patterns of the incidence of Cercospora leaf spot (caused by Cercospora zonata) in 54 plots (each with 18 plants per $2.0 \mathrm{~m}$ of a two-row plot) of resistant line 1322/2 and susceptible Farah of faba bean (Vicia faba) in field trials (unrandomized plots are shown in this figure for simplicity) conducted at the Turretfield Research Centre, South Australia, Australia, in 2005 and 2006. Each pixel represents one plant grown in soil with a history of a 3-year rotation of faba bean (positive soil zone) or in soil with no history of faba bean (negative soil zone). Plots were aligned on the boundary $(0 \mathrm{~m})$ of the positive $(+)$ and negative $(-)$ soil zones at each of four distances $( \pm 4,8,12$, and $16 \mathrm{~m})$ from the boundary. Each pixel is shaded to indicate the time (days after sowing [DAS]) when Cercospora leaf spot lesions were first observed (as indicated in the legend). often used in management of Cercospora diseases to reduce inoculum survival. However, widespread adoption of minimum-tillage practices to increase organic matter and improve soil structure in Mediterranean climates, such as in southern Australia, can lead to slow decomposition of residues, particularly during long periods of hot, dry conditions during the noncropping phase over summers. As a result, retaining stubble may promote survival of plant pathogens (Boosalis et al. 1986; Sumner et al. 1981) and, perhaps, has played a role in the increase of Cercospora leaf spot in Australian faba bean crops.

The objectives of this study were to understand (i) the role of soilborne inoculum in establishment of Cercospora leaf spot on faba bean, and the spatial and temporal development of the disease in the vicinity of inoculum; (ii) differences in disease development on resistant and susceptible faba bean cultivars; and (iii) the long-term survival of $C$. zonata in soils in southern Australia, including the role of infested residues in providing soilborne inoculum.

\section{Materials and Methods}

Effects of cropping history on incidence and severity of Cercospora leaf spot-General methods. Two field trials were conducted, one in 2005 and another $300 \mathrm{~m}$ away in a neighboring field in 2006, situated at Turretfield Research Station $\left(34.55^{\circ} \mathrm{S}, 138.83^{\circ} \mathrm{E}\right) 10 \mathrm{~km}$ northeast of Gawler, South Australia. The region has a Mediterranean climate with mean annual rainfall of $460 \mathrm{~mm}, 80 \%$ of which falls from April to October. The trial sites had an elevation of $116 \mathrm{~m}$, and a redbrown loam soil typical of most fields in this region.

In both years the field trial spanned two distinct soil zones within a field: (i) a zone where faba bean had been grown every 3 years since 1997 and had a history of natural establishment of Cercospora leaf spot (designated the positive soil zone) and (ii) a second zone immediately adjoining the first zone and with no history of faba bean cropping (designated the negative soil zone). Each trial was arranged in this field such that $50 \%$ of plots were planted in the positive soil zone and $50 \%$ in the adjoining negative soil zone. This arrangement did not allow for replication of the soil zones.

Two genotypes of $V$. faba were examined, hereafter referred to as lines. One line was susceptible ('Farah'; Heritage Seeds Pty. Ltd., Adelaide, Australia) and the other resistant (breeding accession 1322/2) to Cercospora leaf spot (Kimber and Paull 2011). Each trial consisted of 54 plots arranged as nine blocks of six plots (Fig. 1). Three replicates of the resistant line and the susceptible line were allocated randomly to the six plots in each block. Two faba bean buffer plots separated each experimental plot, and $2 \mathrm{~m}$ of bare ground separated each block of plots. Each year the trial was positioned so that four blocks of plots (24 plots) were in the positive soil zone and four blocks in the negative soil zone, with the middle block ( 6 plots) placed on the border of these soil zones. The center of each block was positioned at $4,8,12$, or $16 \mathrm{~m}$ from the border (the latter designated as $0 \mathrm{~m}$ ) within each positive and negative soil zone. An illustration of the spatial design of each trial is presented in Figure 1, showing the positioning of blocks within the two soil zones (note that the buffers are not presented and plots have been reordered within each block to present the resistant and susceptible lines separately). Each plot was $2.0 \mathrm{~m}$ long and consisted of two rows spaced $25 \mathrm{~cm}$ apart, with faba bean plants spaced $25 \mathrm{~cm}$ apart within rows that were sown by hand to a 4-cm sowing depth, with 9 seeds/row. There was a $50-\mathrm{cm}$ space between adjacent plots. After sowing, the furrows were scarified lightly to ensure good seed-bed coverage. Fungicides were not applied to the plants in order for Cercospora leaf spot to establish by natural infection. Weather data, including daily rainfall and temperature, were recorded on site via an automated weather station at the research station.

Incidence of Cercospora leaf spot. In 2005, the field trial described above was sown on 12 May, and the incidence of disease on each plant was recorded weekly from 42 days after sowing (DAS) (30 June) to 112 DAS (1 September). In 2006, the trial was sown in the neighboring field, as described above, on 25 May and disease incidence data recorded weekly from 56 DAS (19 July) to 112 DAS (13 September). For each field trial, $\chi^{2}$ analyses were performed using Microsoft Excel for mean disease incidence data each 
week to examine the effect of faba bean genotype and soil zone on disease development. The block of plots on the boundary between the positive and negative soil zone $(0 \mathrm{~m})$ was omitted from the analyses. The incidence (presence or absence) of Cercospora leaf spot for individual plants was also recorded on a spatial map in Excel. An individual cell in Excel represented an individual plant, and the cells were formatted with three colors to identify three time periods when disease was first observed on plants: 49 to 63 DAS, 70 to 84 DAS, and 91 to 112 DAS. Disease prevalence maps were then constructed to visualize the spatial pattern of disease development on plants of both faba bean lines within the positive and negative soil zones for each of the three time periods in each year (Fig. 1).

Severity of Cercospora leaf spot. Commencing at the first observation of Cercospora leaf spot, six plants in the center of each plot described above were assessed for: the number of leaves on each plant on the main stem, the number of leaves with Cercospora leaf spot lesions, the visually estimated leaf area diseased (\%LAD) on each leaf, and the number of nodes from which leaves had abscised. In 2005, these data were recorded for all 54 plots from 49 to 84 DAS. From 91 to 105 DAS, one plot of each of the resistant lines and susceptible lines within each block was omitted from rating to save time but retain balanced data sets between soil zones, resulting in 36 plots assessed; and in the final assessment at $112 \mathrm{DAS}$, all plots positioned on the boundary $(0 \mathrm{~m})$ and adjacent plots on the negative soil zone $(-4 \mathrm{~m})$, as well as one central block of plots within the positive soil zone $(+8 \mathrm{~m})$, were excluded due to time constraints, resulting in 24 plots assessed. In addition, disease was recorded using time-lapse digital photography (Nikon Coolpix 950, Nikon View 6; Nikon Imaging Japan Inc., Tokyo) at weekly intervals from 63 to 98 DAS on one leaf pair selected arbitrarily on plants sown in the 12-m plots in each of the positive and negative soil zones. In 2006, the severity of Cercospora leaf spot was assessed as described above in all 54 plots from 56 to 98 DAS, on 36 plots from 105 to 112 DAS, and in 24 plots in the final assessment at 119 DAS, omitting plots located on the boundary $(0 \mathrm{~m})$ and in blocks located at \pm 8 and $\pm 16 \mathrm{~m}$ to maintain balanced data collection in each soil zone, given the time constraints. Due to drought conditions in 2006, the trial was irrigated once at 98 DAS using overhead sprinklers to provide approximately $25 \mathrm{~mm}$ of water.

Temporal disease severity curves were developed for both the resistant and susceptible lines, and spatial disease severity curves across the two soil zones were developed for disease ratings at 77 and 98 DAS for both lines. These time periods allowed examination of the data prior to and at the peak of defoliation. The percent loss of photosynthetic leaf area (\%LPLA) was used to assess overall Cercospora leaf spot severity, calculated as the sum of total \%LAD and defoliation (equivalent to $100 \% \mathrm{LAD}$ ) that was expressed as the percentage of total plant foliage affected by the disease. Cercospora leaf spot was not observed in the first 42 DAS in the 2005 trial; therefore, only data for evaluation dates after this were included in the analyses. Disease data (\%LPLA) were square-root transformed when required to normalize the data. Raw \%LPLA data for each line and soil zone position were plotted against DAS, and data were fitted to exponential or logistic standard curves using Genstat (version 11; VSN International Ltd., Hemel Hempstead, UK). The best-fit model was determined by significance at $P \leq 0.05$, and the percentage of variance by the model explained. The fitted values and residual mean square values of \%LPLA per line in each block were calculated for 77 and 98 DAS. The mean standard error values were calculated from the residual mean square values, which also accounted for data points at either side of the selected time periods (i.e., 70 and 84 DAS). The estimated values at 77 and 98 DAS for each line and for each position between and within each soil zone were compared using a twosample $t$ test at $P=0.05$. Plots sown at $+16 \mathrm{~m}$ were omitted from the main analyses because these plots were on the outer perimeter of the area of the field that had been planted with faba bean every 3 years and, therefore, were similar to the 0 -m boundary area. Cumulative rainfall recorded at each trial site from 49 to 112 DAS were regressed against mean \%LPLA for the susceptible line in the positive soil zone at the $12-\mathrm{m}$ position, and significance of the deviation from 0 was determined at $P<0.05$. The $+12-\mathrm{m}$ position was selected for the central location and avoided edge effects of the soil zone boundaries.
Survival of $C$. zonata in soil. The role of infested faba bean residue in survival of $C$. zonata was examined over 30 months from December 2005 to June 2008 at the Charlick Research Station $\left(35.26^{\circ} \mathrm{S}\right.$, $\left.138.89^{\circ} \mathrm{E}\right)$, located $5 \mathrm{~km}$ south of Strathalbyn, South Australia. The region has a Mediterranean climate with mean annual rainfall of $490 \mathrm{~mm}, 80 \%$ of which falls from April to October, on an elevation of $70 \mathrm{~m}$, with red-brown loam soil typical of most fields in this region.

A previous faba bean field trial, 0.12 ha in size, with natural establishment of Cercospora leaf spot had been conducted to evaluate foliar fungicide treatments. This trial was harvested in December 2005, resulting in deposition of $C$. zonata-infested crop residues on the soil surface. On 20 December 2005, immediately following harvest, a residue trial was established over three nonfungicide-treated control plots of that 2005 trial, with each plot estimated to have approximately $600 \mathrm{~g}$ of infested residues on the soil surface. Each of the original plots was divided lengthwise to create three plots of residue treatments (each 1.6 by $2.0 \mathrm{~m}$ ). Hence the residue trial was arranged as a randomized complete block design with three replicate blocks, each with three treatments: (i) faba bean residue retained on the soil surface, (ii) faba bean residues removed manually from the soil surface, and (iii) faba bean residues grazed by sheep. Plots for each of the first two treatments were enclosed by $1-\mathrm{m}$-tall steel-mesh fencing to exclude grazing animals. Weed infestation was controlled by spot applications of glyphosate $(10 \mathrm{ml} / \mathrm{liter})$ with a backpack sprayer, when necessary.

In all, 35 soil cores (each $2.5 \mathrm{~cm}$ in diameter and $10 \mathrm{~cm}$ deep) were extracted from each plot at the beginning of the trial ( 0 months) and every 3 months thereafter for 27 months (10 sampling times). The soil cores were oven dried for 4 days at $40^{\circ} \mathrm{C}$, then placed in cold storage $\left(4^{\circ} \mathrm{C}\right)$. In June 2008 , the relationship between C. zonata soilborne inoculum and Cercospora leaf spot severity was tested for the soils sampled at $0,9,18$, and 27 months from the plots with retained and removed residues using a pot-bioassay in a completely randomized design, with three replicates of the two residue treatments and a control soil treatment. Soil with no history of faba bean cropping, collected from a site at the University of Adelaide's Charlick Research Station, was included as a control treatment. In total, 27 pots (each $15 \mathrm{~cm}$ in diameter) filled with pasteurized University of California potting mix (University of California, Davis) were each sown with 4 seeds of the Farah at a $3-\mathrm{cm}$ depth, then covered with a $1-\mathrm{cm}-$ deep layer of soil of the appropriate soil treatment. Pots were then watered to soil capacity and maintained outside at the University of Adelaide Waite Campus (Urrbrae, South Australia, Australia) and irrigated with overhead misting from 9 July to 3 September 2008 . The pots were placed $40 \mathrm{~cm}$ apart to minimize the risk of cross-contamination. Seedlings were assessed for Cercospora leaf spot 8 weeks after sowing at the five-node growth stage as the average \%LAD on each leaf pair.

After completion of soil sampling, 30 months after commencement of the field trial in 2005, the infectivity of inoculum in each plot was assessed in situ. The fencing was removed and seven furrows, spaced $25 \mathrm{~cm}$ apart along the length of each plot, were prepared manually to minimize transfer of soil between plots. On 25 June 2008, each plot was sown with seed of the Farah $\left(20\right.$ seeds $\left./ \mathrm{m}^{2}\right)$ at a $4-\mathrm{cm}$ depth. When seedlings reached the five-node growth stage at 63 DAS (26 August), the average \%LAD and defoliation (\%) were assessed on the lower $50 \%$ of the canopy of plants within each plot, excluding those on the perimeter of the plots to avoid interplot interference.

Cercospora leaf spot data from the pot assay were transformed (square-root) when required for normality of data and subjected to analysis of variance (ANOVA) at the sampling times 0, 9, 18, and 27 months, using Genstat, version 11. Significant differences among treatments were assessed at $P \leq 0.05$. Disease data from the in situ field assay were analyzed using ANOVA and mean \%LAD per plant from the pot assay using GraphPad Prism (version 5; GraphPad, San Diego, CA).

\section{Results}

Effects of cropping history on the incidence of Cercospora leaf spot of faba bean. Cercospora leaf spot was first observed on susceptible Farah sown in the positive (infested) soil zone at 49 DAS in 2005 and 56 DAS in 2006. The lesions were observed on the 
lowest two leaves (three- to four-node growth stage) of seedlings distributed throughout the plots of Farah (2.4 and $72.5 \%$, respectively). By comparison, lesions on seedlings sown in the negative soil zone were first observed 1 week later than in the positive soil zone in both years. Sporulation on primary leaf lesions was observed 1 to 2 weeks after symptoms were first observed, by which time lesions exceeded $8 \mathrm{~mm}$ in diameter.

In 2005 and 2006, disease incidence increased rapidly on the susceptible Farah sown in the positive soil zone, resulting in lesions on 92 to $98 \%$, respectively, of plants at 63 DAS (Fig. 1). This was a significantly greater disease incidence than on plants of the susceptible line sown in the negative soil zone in 2005 (29.8\%) and 2006 $(55.3 \%)\left(\chi^{2}{ }_{1}=32.2, P<0.001\right.$ in 2005 and $\chi^{2}{ }_{1}=12.1, P<0.001$ in 2006) at this assessment period. The maximum disease incidence of 80 to $100 \%$ on Farah in the negative soil zone was reached at 70 to 98 DAS; hence, no significant difference $\left(\chi^{2}{ }_{1}<0.016, P>0.35\right)$ was measured in disease incidence between the positive and negative soil zones at these later disease assessment times.

The incidence of Cercospora leaf spot on line 1322/2 was significantly less $\left(\chi_{6}^{2}=171.7, P<0.001\right)$ than on Farah in both the positive and negative soil zones in both the 2005 and 2006 trials. Disease was first observed in the positive soil zone from 49 to 63 DAS on fewer than $5 \%$ of the seedlings of line $1322 / 2$. From 70 to 84 DAS, disease incidence was significantly greater on this line in the positive soil zone than on plants in the negative soil zone in both years (62 and $18 \%$, respectively, with $\chi^{2}{ }_{1}=27.9, P<0.001$ in the 2005 trial; and 47 and $6 \%$, respectively, with $\chi^{2}{ }_{1}=33.3, P<0.001$ in the 2006 trial). This is illustrated by gray-shaded cells in a spatial map of disease incidence on line $1322 / 2$ at 70 to 84 DAS in both years in Figure 1. At 98 DAS, 93\% of plants of line 1322/2 in the 2005 trial and $89 \%$ of plants of that line in the 2006 trial within the positive soil zone exhibited small lesions typical of Cercospora leaf spot, which was significantly greater $\left(\chi^{2}{ }_{1}=17.2\right.$ in 2005 and 50.5 in 2006 at $P<0.001$ ) than $44 \%$ of plants in the 2005 trial and $16 \%$ of plants in the 2006 trial, respectively, within the negative soil zone.

At assessments from 49 to 63 DAS, the incidence of Cercospora leaf spot on Farah seedlings in the negative soil zone decreased with increasing distance from the positive soil zone (Fig. 1). Mean disease incidence on plants of Farah located $-4,-8,-12$, and $-16 \mathrm{~m}$ from the border with the positive soil zone at 63 DAS was $65,35,13$, and 6\%, respectively, in 2005, and 75, 65, 51, and 30\%, respectively, in 2006. A similar gradient was evident for $1322 / 2$, resulting in a rapid decline in disease incidence with increasing distance from the positive soil zone, though many plants of this line remained symptomless (Fig. 1).

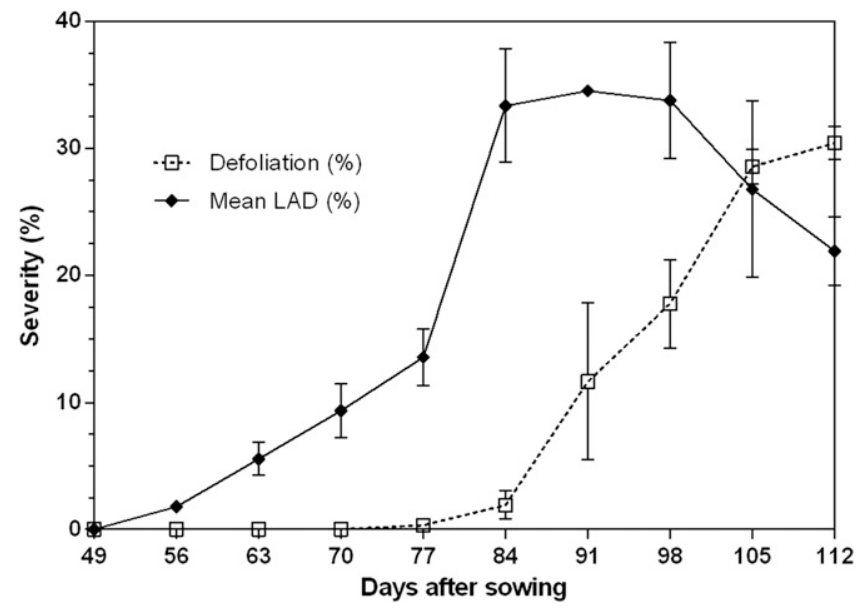

Fig. 2. Severity of Cercospora leaf spot (Cercospora zonata) on faba bean (Vicia faba) over time (days after sowing [DAS]) measured as the leaf area diseased (\%LAD) and mean defoliation (percent leaves abscised) on plants of susceptible Farah grown in soil where faba bean had been grown every 3 years. Plants were grown in plots $4 \mathrm{~m}$ from the edge of infested soil. Each data point represents the mean \pm standard errors of the mean for $n=48$ (49 DAS) to $n=240$ (112 DAS) observations.
At the final assessment (98 DAS), disease incidence in 1322/2 plots -4 to $-16 \mathrm{~m}$ from the border decreased from 72 to $17 \%$ in 2005 and 32 to $6 \%$ in 2006 but was $100 \%$ on Farah plants in the same positions. No disease gradients were observed on either faba bean line in the positive soil zone in both years at the final disease rating.

Effects of cropping history on the severity of Cercospora leaf spot of faba bean. This spatial distribution of disease between the two soil zones was also investigated using disease severity data. In severely diseased plots, Cercospora leaf spot lesions expanded and coalesced from 49 to 98 DAS, causing significant necrosis, with the maximum mean \%LAD recorded at approximately 91 DAS (e.g., $35 \%$ LAD in +4 m plots; Fig. 2). Defoliation of the lowest leaves in the canopy infected with Cercospora leaf spot commenced at 77 DAS (Fig. 2), causing a decline in measurable mean \%LAD after 98 DAS. Therefore, data for \%LAD and defoliation were combined to calculate the total \%LPLA to quantify the severity of Cercospora leaf spot. Disease was most severe on the lower $50 \%$ of the canopy of Farah in the positive soil zone plots at 98 DAS (mean \pm standard error: $72 \pm 6.0 \%$ LPLA in 2005 and $53 \pm 2.7 \%$ LPLA in 2006), particularly due to defoliation on the three nodes closest to the soil surface $(85 \pm 4.3 \%$ LPLA $)$, whereas mean disease severity was only $2 \pm 0.7 \%$ LPLA in 2005 and $0.02 \pm 0.02 \%$ LPLA in 2006 in the upper $50 \%$ of the canopy. In both years, disease development on Farah plants at $12 \mathrm{~m}$ (central block) within the positive soil zone showed a rapid increase in severity from 77 to 91 DAS. There was minimal increase in disease severity during this period on Farah plants in the negative soil zone and on the resistant line 1322/2 in either soil zone (Fig. 3). In the positive soil zone, Farah plants showed $>10 \%$ LPLA by 77 DAS, which progressed to $>50 \%$ LPLA by 98 DAS from lesion expansion and defoliation (Figs. 3 and 4).

Cercospora leaf spot on Farah was more severe in 2005 (maximum mean LPLA $=44.5 \pm 2.4 \%)$ than in $2006(29.5 \pm 0.8 \%)$ in the positive soil zone. Rainfall was $29 \%$ greater and $22 \%$ less than the longterm average (1887 to 2010) for the entire years of 2005 and 2006, respectively (Bureau of Meteorology 2010). In 2005, 13 rain events that each exceeded $5 \mathrm{~mm}$ were recorded between July and October (Fig. 3C), whereas there were only 6 such rain events in 2006 (Fig. 3D). There was a significant regression in $2005\left(R^{2}=0.78\right.$ at $P \leq$ $0.001)$ and $2006\left(R^{2}=0.74\right.$ at $\left.P \leq 0.001\right)$ between disease severity (mean \%LPLA) on the susceptible Farah in the positive soil zone at $12 \mathrm{~m}$ and cumulative rainfall each season from 49 to 112 DAS. In both trials, the increase in \%LPLA over time $(y)$ on the susceptible Farah in the positive soil zone fitted a logistic curve. For example, for +12 m blocks, $y=2.66+46.08 /[1+\exp (-0.23 \times(X-40.92)]$ in 2005 and $y=0.49+5.02 /[1+\exp (-0.14 \times(X-28.30)]$ in 2006 ; with both regressions significant at $P<0.001)$. In each trial, disease was most severe in plots positioned at $+4,+8$, and $+12 \mathrm{~m}$. In contrast, Cercospora leaf spot (\%LPLA) was significantly less severe on Farah in the negative soil zone, and severity over time $(y)$ fitted an exponential curve (e.g., for $-12 \mathrm{~m}$ blocks, $y=0.23+0.77 \times 1.04^{X}$ in 2005 and $y=0.44+0.56 \times 1.04^{X}$ in 2006 , both at $\left.P<0.001\right)$. Disease on the resistant line $1322 / 2$ was $<20 \%$ LPLA in both soil zones (Fig. 3).

The fitted means of \%LPLA at 77 and 98 DAS, calculated using nonlinear regression analyses for the two lines, are presented in Figure 5A (2005) and Figure 5B (2006). The \%LPLA scores at 77 DAS were attributed solely to the \%LAD, because this rating occurred prior to the onset of defoliation (Fig. 2). This was also the earliest that Cercospora leaf spot was observed on either line in either soil zone. The assessment at 98 DAS represented the upper asymptote of disease severity on the susceptible Farah in the positive soil zone (Fig. 3). The paired two-sample $t$ tests of mean \%LPLA across the soil zones showed that disease was significantly more severe on the susceptible Farah $(P<0.001)$ in the positive soil zone than in the negative soil zone in both years (Table 1) at both 77 DAS (2005 trial: $t=11.33$ and 2006 trial: $t=25.65$, with both at $P<0.001)$ and 98 DAS (2005 trial: $t=32.75$ and 2006 trial: $t=41.49$, with both at $P<0.001)$. In addition, disease severity was significantly different $(P<0.001)$ for both 77 and 98 DAS in paired planting positions in the positive versus negative soil zones (e.g., -8 versus $+8 \mathrm{~m}$; Table 1). In both trials, there was a substantial decrease in disease 
severity in the negative soil within $4 \mathrm{~m}$ of the boundary with the positive soil zone (Fig. 5). In both years, Cercospora leaf spot was significantly $(P<0.001)$ more severe at 77 DAS on plants at $0 \mathrm{~m}$ $(11 \pm 0.7 \%$ LPLA) than on plants located at $-4 \mathrm{~m}(4 \pm 0.5 \%$ LPLA in $2005, t=5.34$ and $2 \pm 0.6 \%$ LPLA in 2006, $t=12.95$ ), and on plants located at $-8 \mathrm{~m}$, where severity was similar to that at $-4 \mathrm{~m}$ (Fig. 5; Table 1). Disease at $0 \mathrm{~m}$ was also significantly more severe $(P<0.001)$ at 98 DAS $(33 \pm 1.1 \%$ LPLA in 2005 and $23 \pm 0.2 \%$ LPLA in 2006) than on plants located at $-4 \mathrm{~m}(12 \pm 0.5 \%$ LPLA in 2005 and $7 \pm 0.6 \%$ LPLA in 2006) and $-8 \mathrm{~m}(15 \pm 0.6 \%$ LPLA in 2005 and $7 \pm 0.7 \%$ LPLA in 2006) (Fig. 5; Table 1).

Cercospora leaf spot on breeding line 1322/2 was considerably less severe than on Farah in both 2005 and 2006, and did not exceed $16 \%$ LPLA by 112 DAS within the positive soil zone $(11.0 \pm 2.0 \%$ LPLA in 2005 and $15.9 \pm 1.2 \%$ LPLA in 2006) Nevertheless, significant $(P<0.05)$ differences in disease severity were observed in both years at 98 DAS between plants in the negative soil zone $(1 \pm 0.1 \%$ LPLA in 2005 and 0\% LPLA in 2006) and those in the positive soil zone ( $3 \pm 0.3 \%$ LPLA in 2005 and $5 \pm 0.5 \%$ LPLA in 2006) (Fig. 5). The difference in severity between the two soil zones was also significant $(P<0.05)$ at 77 DAS in 2006 but not in 2005 , when the mean \%LPLA was 0 at this time period (Table 1).

Survival of $\boldsymbol{C}$. zonata in soil. At the first sampling ( 3 months), few visible fragments of faba bean residue were evident on the surface of the grazed plots. Conversely, in plots where the residues were retained on the soil surface, the residues were still visible on the soil surface after 27 months. Although efforts were made to exclude residues from the removed residue plots, fragments $<20 \mathrm{~mm}$ long were occasionally observed on these plots as a result of wind dispersal from adjacent plots.

When the infectivity of soil samples collected from the retained or removed plots at $0,9,18$, and 27 months was tested on Farah plants in the pot assay, Cercospora leaf spot was first observed at 6 weeks after sowing. At 8 weeks after sowing, Cercospora leaf spot was significantly $(P=0.004)$ more severe $(>50 \%$ LAD) on seedlings grown in soil with residues retained than on plots with residues removed $(<15 \%$ LAD) (Fig. 6A). Plants grown in soil with residues retained and collected at the first sampling were more severely diseased than those grown in soil collected 9 months later, after which disease severity did not change significantly (Fig. 6A). Disease severity on plants grown in soil with residues removed $(12.2 \pm 2.4 \%$ LAD) were statistically comparable $(P>0.05)$ with that on plants in the control soil $(3.8 \pm 2.0 \% \mathrm{LAD})$, and changed little $( \pm 2.0 \% \mathrm{LAD})$ over the four times of sampling. These control plants grown on soil not previously used for faba bean exhibited limited Cercospora leaf spot, possibly due to cross-contamination from residues on adjacent plots.

The in situ field assay, conducted 30 months after harvest of the 2005 field trial, revealed significant $(P<0.001)$ differences in Cercospora leaf spot severity among all three residue treatments (Fig. 6B). The disease at 9 weeks after sowing was more severe $(P<0.001)$ on seedlings grown in soil with residues retained $(48 \pm 0.6 \% \mathrm{LAD})$ than in the grazed plots $(29 \pm 0.9 \%$ LAD $)$ which, in turn, was more severe $(P<0.05)$ than in plots from which residue had been removed $(18 \pm 1.0 \% \mathrm{LAD})$.

\section{Discussion}

This study showed a significant positive association between the incidence and severity of Cercospora leaf spot of faba bean and soilborne inoculum of $C$. zonata in field trials in South Australia. In both growing seasons in this study, lesions typical of Cercospora leaf spot appeared 49 to 63 DAS on the lowest leaves of seedlings of the susceptible faba bean Farah. This incidence was significantly greater within soil that had been planted to faba bean every 3 years since 1997, designated as the positive soil zone, compared with soil with no planting history of faba bean production. This association with in situ inoculum, including the initial occurrence of lesions on leaves closest to the soil surface, has been reported for a wide range of pathogens (Campbell and Noe 1985; Vereijssen et al. 2006; Windels et al. 1998). The incidence of infection in the susceptible line $1322 / 2$ planted within the infested soil zone increased rapidly so that all emerged
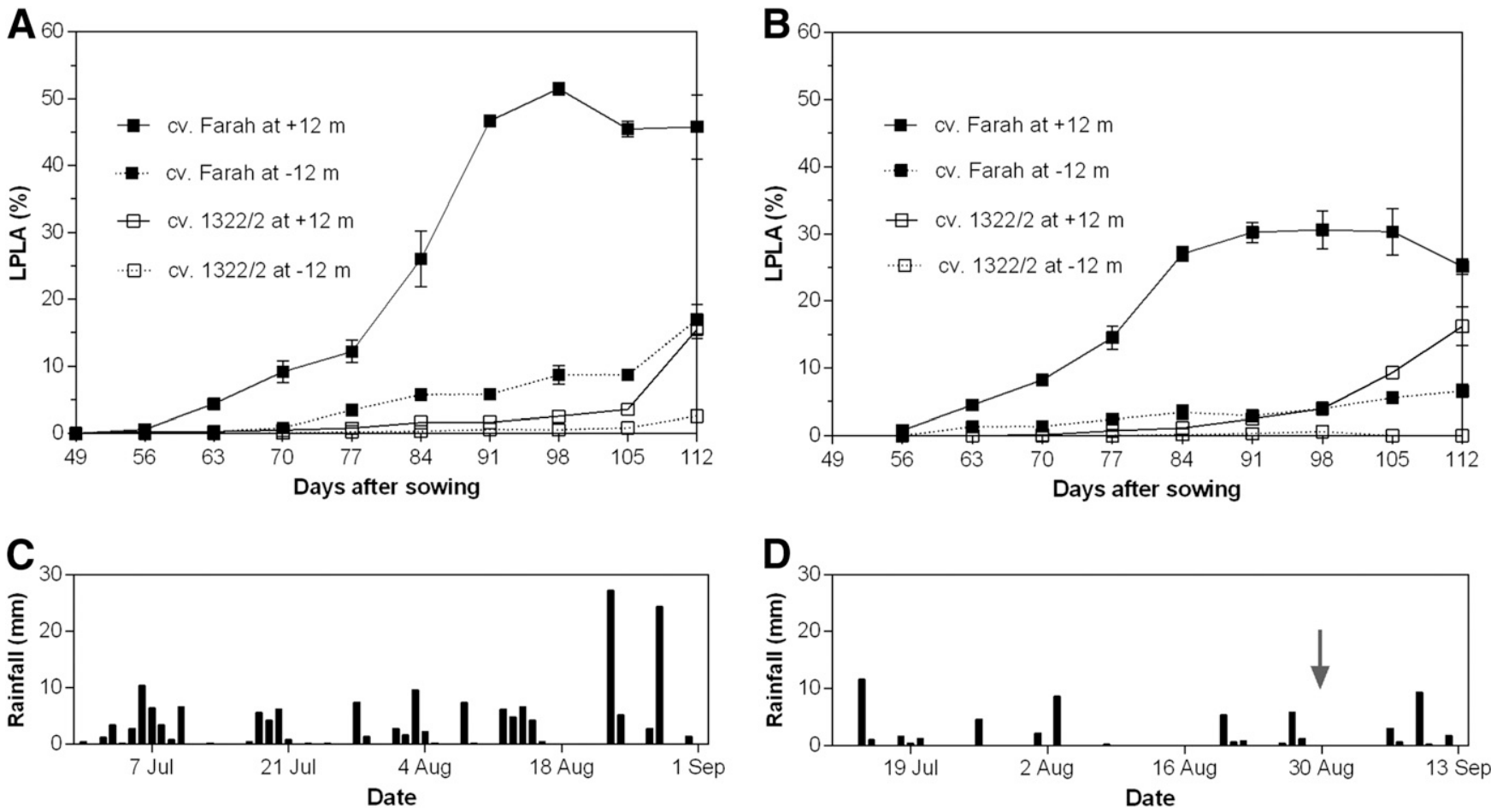

Fig. 3. Severity of Cercospora leaf spot on two faba bean (Vicia faba) lines-breeding line 1322/2 (resistant) and Farah (susceptible) — grown in an infested (positive [+]) soil zone in which faba bean had been grown every 3 years, and in a noninfested (negative [-]) soil zone without a history of faba bean cropping. Disease severity, measured as the loss of photosynthetic leaf area (\%LPLA), was recorded each week from 49 to 112 days after sowing (DAS) in a field trial in A, 2005 and B, 2006. Rain events were recorded during the same time period for C, 2005 and D, 2006. Plots for each faba bean line were positioned near the center of each soil zone $(12 \mathrm{~m}$ from the border between the infested and noninfested soils). The arrow indicates the timing of an irrigation in 2006 equivalent to a 25-mm rain. Each data point represents the mean \pm standard error of $n=48$ (49 DAS) to $n=240$ (112 DAS) observations. 
plants exhibited lesions within 2 weeks of the first appearance of symptoms. Because the latent period of C. zonata on faba bean is 10 to 14 days (R. B. E. Kimber, unpublished data), this was probably a response to infection by primary soilborne inoculum.

The temporal and spatial dynamics of Cercospora leaf spot on a susceptible faba bean cultivar and a resistant faba bean line that resulted from soilborne inoculum in the field is described in this study. Nonlinear regressions using a logistic curve best described disease progress over time on the susceptible line grown in soil where Cercospora leaf spot inoculum had established following regular cropping of faba bean, whereas an exponential model best described disease severity over time on the susceptible line with increasing distance from the inoculum source; the same was found for the resistant cultivar in both soil zones. Both regressions may provide useful information for disease management strategies such as residue management and isolation of crops from residues infested from previous years (Madden et al. 2007; Zhang et al. 2004).

Cercospora leaf spot on susceptible plants in soil that had no history of faba bean production (negative soil zone) was observed a week later (56 DAS) than on the positive soil zone, at which time the incidence of

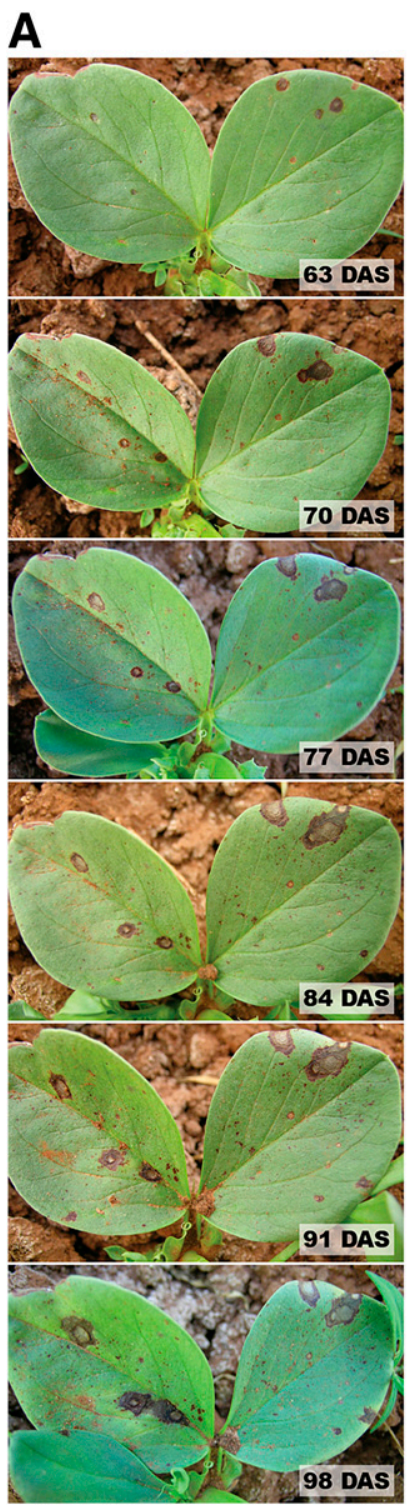

B

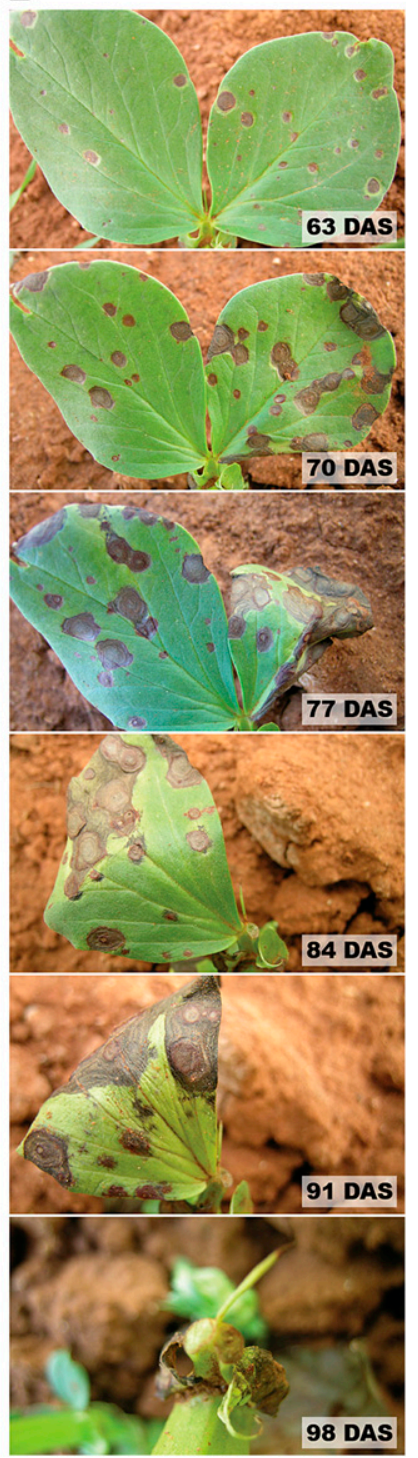

Fig. 4. Cercospora leaf spot (Cercospora zonata) recorded each week (days after sowing [DAS]) using time-lapse photography of the same leaf pair in the lower canopy of the faba bean (Vicia faba) Farah (susceptible to Cercospora leaf spot) grown in soil $\mathbf{A}$, with no history of faba bean production and $\mathbf{B}$, sown every 3 years with faba bean. diseased seedlings decreased with increasing distance from the positive soil zone. The temporal and spatial patterns of disease incidence within the two soil zones indicated that primary inoculum that infected plants in the noninfested negative soil zone originated from the adjacent, infested, positive soil zone from either splashborne or windborne spores. An alternative explanation, that a limited amount of inoculum may have been present in the negative soil zone, is unlikely because the time of disease onset would have been similar in both soil zones (Madden et al. 2007; Vereijssen et al. 2006). The fact that the incidence of Cercospora leaf spot increased rapidly in the negative soil zone after 77 DAS reflects secondary infections (Vereijssen et al. 2007).

Defoliation in the lower 50\% of the canopy, where Cercospora leaf spot was most severe, in addition to lesion formation and expansion (\%LAD), were important components of disease severity on faba bean; therefore, these variables were combined to describe the \%LPLA and to quantify Cercospora leaf spot severity. This has been used to describe severity and yield loss caused by other Cercospora diseases (Berger 1977; Berger et al. 1997; Muro et al. 2001; Proulx and Naeve 2009). Furthermore, at 98 DAS, the defoliation observed on plants attributed to Cercospora leaf spot had occurred prior to other factors affecting defoliation, such as moisture stress or natural senescence of the lower leaves (data not shown). Disease severity midseason (measured as \%LPLA) was greatest on plants that had

A

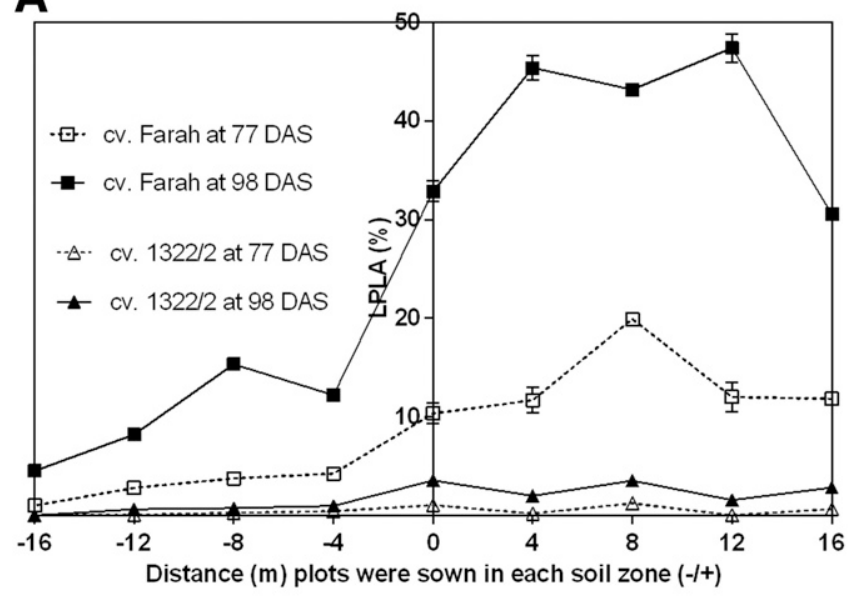

B

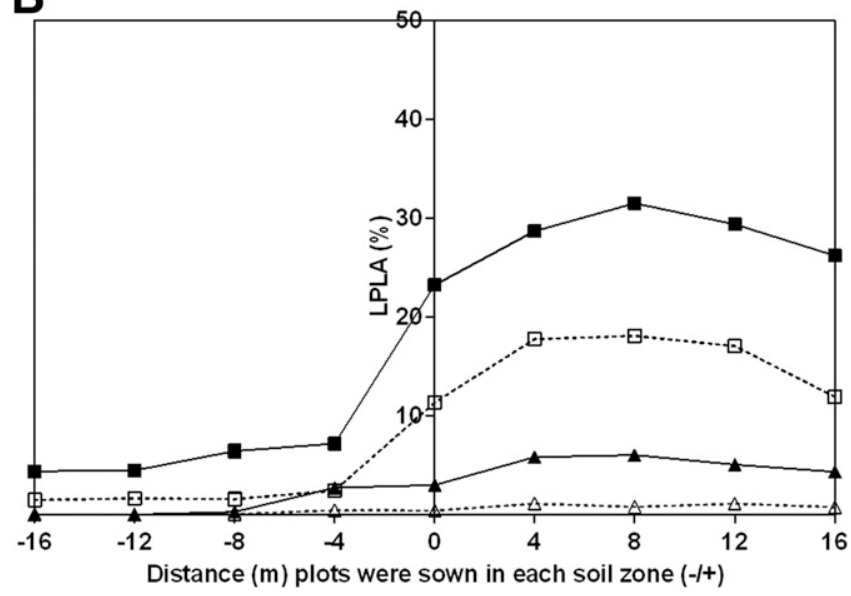

Fig. 5. Cercospora leaf spot severity (mean percentage loss of photosynthetic leaf area [\%LPLA]) in A, 2005 and B, 2006 trials calculated using fitted values from nonlinear regressions at 77 and 98 days after sowing (DAS) for faba bean breeding line 1322/2 (resistant to Cercospora leaf spot) and Farah (susceptible) planted four distances $(4$ to $16 \mathrm{~m})$ in a positive $(+)$ soil zone where faba bean was grown every 3 years and a negative (-) soil zone with no history of faba bean cropping, and on the boundary $(0 \mathrm{~m})$ separating the two soil zones. Each data point represents the mean \pm standard error of three replicate plots. 
exhibited primary infection early in the season (by 49 DAS), whereas disease was considerably less severe when primary infection occurred later (63 DAS). This suggests that the timing of primary infection is an indicator of potential \%LPLA during the vegetative and reproductive stages of plant growth, provided conditions remain favorable for disease development. This reflects the significant positive relationship between disease severity and accumulated rainfall between 49 and 112 DAS in both seasons, although drought conditions in 2006 reduced disease severity compared with the wetter 2005 season.

C. zonata was dispersed from soilborne inoculum over relatively short distances in this study. A distinct disease gradient was apparent for both the incidence and severity of Cercospora leaf spot on susceptible and resistant lines sown 0 to $4 \mathrm{~m}$ from the positive soil zone; accordingly, the infested positive soil zone served as an area of inoculum, as defined by Madden et al. (2007). Maps of the temporal and spatial patterns of disease incidence, and comparative analysis of disease severity data generated from nonlinear regressions of \%LPLA, identified significant differences in disease onset (49 to 63 DAS) at 77 to 98 DAS on the susceptible faba bean cultivar planted in either soil zone. The gradients for Cercospora leaf spot on faba bean were relatively steep in both years, shown by a reduction in disease incidence and severity on plants located $4 \mathrm{~m}$ from the positive soil zone. Furthermore, the principal dispersal of $C$. zonata from soilborne inoculum is likely in the form of conidia splashed by rain over short distances, resulting in infection of the lower leaves of nearby plants, and movement of conidia over longer distances by wind or windblown rain. Such mechanisms of dispersal and spatial patterns have been reported for other Cercospora diseases (de Nazareno et al. 1993; McKay and Pool 1918; Nutter et al. 1994; Vereijssen et al. 2006). Steep, within-field dispersal gradients have been attributed to the relatively large size of the conidia of Cercospora spp. (Ward et al.

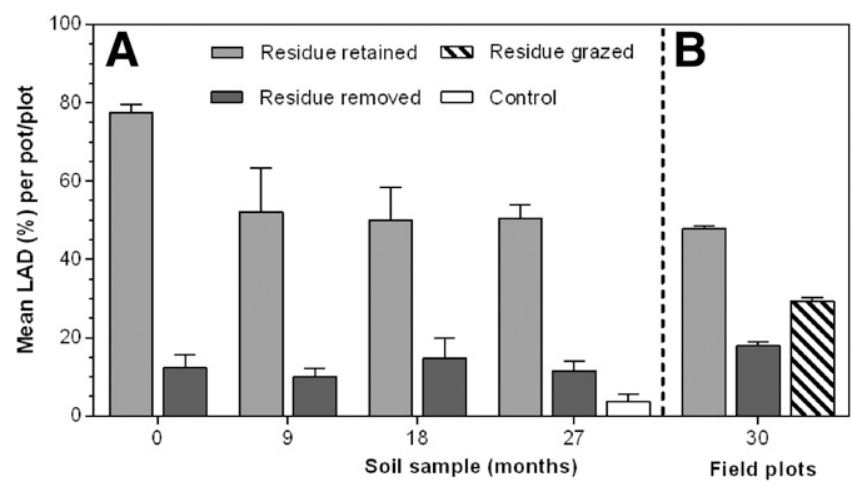

Fig. 6. Mean percent leaf area diseased (\%LAD) caused by Cercospora zonata on Farah faba bean seedlings grown in $\mathbf{A}$, a pot assay using soil collected $0,9,18$, and 27 months from field plots after $C$. zonata-infested residues had been retained or removed from the soil surface (least significant difference at $P \leq 0.05\left[\mathrm{LSD}_{0.05}\right]$ was $12.3 \%(A D)$ and $\mathbf{B}$, an in situ assay in which faba bean seed of the same cultivar were sown in field plots in which residues had been retained, removed, or grazed by sheep 30 months after harvest $\left(\mathrm{LSD}_{0.05}=2.9 \% \mathrm{LAD}\right)$. Control $=$ soil collected near the trial site from a field with no history of faba bean cropping. Each data point represents the mean \pm standard errors for three replicate plots.

Table 1. Comparative analyses of Cercospora leaf spot severity expressed as mean loss of photosynthetic leaf area (\%LPLA) on susceptible Farah and resistant breeding line 1322/2 of faba bean (Vicia faba) in field trials conducted in 2005 and 2006 to examine the effect of soilborne inoculum on disease development

\begin{tabular}{|c|c|c|c|c|c|c|c|}
\hline \multirow[b]{2}{*}{ Trial, line, zone ${ }^{a}$} & \multirow[b]{2}{*}{$\mathbf{S E}^{\mathbf{b}}$} & \multicolumn{3}{|c|}{77 DAS } & \multicolumn{3}{|c|}{98 DAS } \\
\hline & & Diffc $^{c}$ & $t$ Stat $^{\mathrm{d}}$ & $P$ value $^{\mathrm{e}}$ & Diff & $t$ Stat & $P$ value \\
\hline \multicolumn{8}{|l|}{2005} \\
\hline \multicolumn{8}{|l|}{ Farah } \\
\hline$+v e$ versus $-\mathrm{ve}^{\mathrm{f}}$ & 0.928 & 10.91 & 11.33 & $<0.001$ & 31.55 & 32.75 & $<0.001$ \\
\hline$+12 \mathrm{~m}$ versus $-12 \mathrm{~m}$ & 2.343 & 9.22 & 6.02 & $<0.001$ & 39.17 & 25.59 & $<0.001$ \\
\hline$+8 \mathrm{~m}$ versus $-8 \mathrm{~m}$ & 0.459 & 16.17 & 23.87 & $<0.001$ & 27.83 & 41.09 & $<0.001$ \\
\hline$+4 \mathrm{~m}$ versus $-4 \mathrm{~m}$ & 1.850 & 7.45 & 5.48 & $<0.001$ & 33.17 & 24.39 & $<0.001$ \\
\hline $0 \mathrm{~m}$ versus $-4 \mathrm{~m}$ & 1.522 & 6.59 & 5.34 & $<0.001$ & 20.66 & 17.69 & $<0.001$ \\
\hline $0 \mathrm{~m}$ versus $-8 \mathrm{~m}$ & 1.364 & 6.10 & 5.22 & $<0.001$ & 17.51 & 14.19 & $<0.001$ \\
\hline \multicolumn{8}{|l|}{$1322 / 2$} \\
\hline +ve versus $-\mathrm{ve}$ & 0.078 & 0.33 & 1.20 & ns & 1.89 & 6.76 & $<0.001$ \\
\hline$+8 \mathrm{~m}$ versus $-8 \mathrm{~m}$ & 0.031 & 0.97 & 5.52 & $<0.001$ & 2.76 & 15.75 & $<0.001$ \\
\hline$+4 \mathrm{~m}$ versus $-4 \mathrm{~m}$ & 0.239 & -0.25 & -0.50 & ns & 1.03 & 2.10 & $<0.05$ \\
\hline \multicolumn{8}{|l|}{2006} \\
\hline \multicolumn{8}{|l|}{ Farah } \\
\hline +ve versus -ve & 0.317 & 14.44 & 25.65 & $<0.001$ & 23.35 & 41.49 & $<0.001$ \\
\hline$+12 \mathrm{~m}$ versus $-12 \mathrm{~m}$ & 0.246 & 15.43 & 31.14 & $<0.001$ & 24.95 & 50.35 & $<0.001$ \\
\hline$+8 \mathrm{~m}$ versus $-8 \mathrm{~m}$ & 0.524 & 16.54 & 22.85 & $<0.001$ & 25.10 & 34.67 & $<0.001$ \\
\hline$+4 \mathrm{~m}$ versus $-4 \mathrm{~m}$ & 0.435 & 15.32 & 23.22 & $<0.001$ & 21.51 & 32.60 & $<0.001$ \\
\hline $0 \mathrm{~m}$ versus $-4 \mathrm{~m}$ & 0.473 & 8.91 & 12.95 & $<0.001$ & 16.09 & 23.40 & $<0.001$ \\
\hline $0 \mathrm{~m}$ versus $-8 \mathrm{~m}$ & 0.558 & 9.80 & 13.11 & $<0.001$ & 16.84 & 22.54 & $<0.001$ \\
\hline \multicolumn{8}{|l|}{$1322 / 2$} \\
\hline +ve versus $-\mathrm{ve}$ & 0.114 & 0.82 & 2.43 & $<0.05$ & 4.57 & 13.56 & $<0.001$ \\
\hline$+8 m$ versus $-8 m$ & 0.044 & 0.73 & 3.48 & $<0.01$ & 5.76 & 27.61 & $<0.001$ \\
\hline$+4 \mathrm{~m}$ versus $-4 \mathrm{~m}$ & 0.374 & 0.66 & 1.08 & ns & 3.09 & 5.05 & $<0.001$ \\
\hline
\end{tabular}

a Trial, faba bean line, and soil zone. Each trial spanned a positive (infested) soil zone (+) sown to faba bean every 3 years and an adjoining, negative soil zone ( - ) with no history of faba bean crops, arranged as nine blocks, each with three randomized plots of each faba bean line, spanning the two zones. Cercospora leaf spot severity on plants over time in each soil zone was described using nonlinear regressions applied to raw data; logistic curves fitting the response of the susceptible line in the positive soil zone, exponential curves fitting the susceptible line in the negative soil zone, and the resistant line in both soil zones. Fitted values and residual mean square values of \%LPLA per line in each block were obtained for 77 and 98 days after sowing (DAS) and standard error (SE) values were calculated from the residual mean square values. Two-sample, paired $t$ tests were applied to the estimated values to determine significant differences in Cercospora leaf spot severity between (versus) soil zones and among described distances (in meters) of each block from the boundary (0 m) of the positive and negative soil zones.

b Sum of SE.

${ }^{c}$ Difference in fitted \%LPLA.

${ }^{\mathrm{d}}$ Paired $t$ statistic.

${ }^{\mathrm{e}}$ For the two soil zones, $t$ tests were conducted between the fitted values. $P$ value was obtained using $n=24 ; t_{24}(0.05)=2.064, t_{24}(0.01)=2.797, t_{24}(0.001)=$ 3.745 , and $\mathrm{ns}=$ not significant.

${ }^{\mathrm{f}}$ Comparison of Cercospora leaf spot severity within entire positive (+ve) soil zone versus entire negative (-ve) soil zone. 
1999). In this study, disease was observed $16 \mathrm{~m}$ from the positive soil zone, indicating that conidia were dispersed at least as far as $16 \mathrm{~m}$. In this context, a survey of commercial crops in southern Australia showed that the incidence and severity of Cercospora leaf spot were greater in crops adjacent to than remote from fields with infested faba bean residues from the previous season (R. B. E. Kimber, unpublished data). Further investigation of the survival of $C$. zonata and dispersal over distances greater than $16 \mathrm{~m}$ is required to determine the influence of infested crop residues on subsequent infection of nearby faba bean crops.

The severity of Cercospora leaf spot on the susceptible faba bean cultivar in this study was significantly positively correlated with the amount of infested crop residue remaining on the soil surface. $C$. zonata survived in soil at least 30 months, at which time the remaining inoculum was capable of causing severe disease under field conditions, which supported results from two field trials in which disease was observed on faba bean planted in soil that had been sown with faba bean every 3 years since 1997 (i.e., three to four faba bean crops). Survival of other Cercospora pathogens on crop residues has been reported to range from 1 to 3 years (Latterell and Rossi 1983; Nagel 1938) but the inoculum potential can decrease when residues are buried (Khan et al. 2008; McKay and Pool 1918). Therefore, although expansion of the area in southern Australia planted to faba bean over the last three decades and the susceptibility to Cercospora leaf spot of commercial cultivars grown currently (Kimber and Paull 2011) may have contributed to the increased prevalence and severity of Cercospora leaf spot in this region, the persistence of $C$. zonata-infested crop residues as a result of adoption of minimum tillage and drought conditions also are likely important. Retention of crop residues on the soil surface has been associated previously with an increase in prevalence of disease and inoculum of other Cercospora pathogens (Khan et al. 2008; Payne and Waldron 1983; Ringer and Grybauskas 1995). The life cycle of many Cercospora spp. is poorly understood, though it has been suggested that, if a sexual state does exist, the fungus would reside in the genus Mycosphaerella (Groenewald et al. 2006). Until the teleomorph of C. zonata is identified, critical aspects of the survival and dispersal mechanisms of primary inoculum may remain uncertain.

The evaluation of Cercospora leaf spot on faba bean in this study demonstrates an association between soilborne inoculum from infested faba bean residues and the incidence and severity of Cercospora leaf spot. This provides evidence of the role of short rotations ( 1 to 4 years) between faba bean crops on the increased incidence and severity of the disease in southern Australia. The knowledge gained from this study can be used to describe Cercospora leaf spot development in susceptible faba bean crops (i.e., in fields where inoculum is likely to be prevalent), and to optimize the use of foliar fungicide applications to control primary and secondary infections and reduce losses caused by the disease.

\section{Acknowledgments}

We thank M. Russ (Plant Health \& Biosecurity, SARDI), K. James, and I. Roberts (School of Agriculture, Food \& Wine, University of Adelaide) for invaluable technical support; M. Salam (Department of Agriculture and Food, Perth, Western Australia, Australia) for assistance with spatial maps; B. Carrocci (Arris Pty. Ltd., Urrbrae, South Australia, Australia) for image compilation; K. Smith (School of Agriculture, Food \& Wine, University of Adelaide) for assistance on the long-term field trial; and B. Gogel (School of Agriculture, Food \& Wine, University of Adelaide) for statistical advice. This work was conducted as part of the Ph.D. studies of R. Kimber, with support from the Grains Research and Development Corporation, SARDI, and the University of Adelaide.

\section{Literature Cited}

Berger, R. D. 1977. Application of epidemiological principles to achieve plant disease control. Annu. Rev. Phytopathol. 15:165-181.

Berger, R. D., Bergamin Filho, A., and Amorim, L. 1997. Lesion expansion as an epidemic component. Phytopathology 87:1005-1013.

Boosalis, M. G., Doupnik, B. L., and Watkins, J. E. 1986. Effect of reduced tillage on plant diseases. Pages $389-408$ in: No-Tillage and Surface Tillage
Agriculture. M. A. Sprague and G. B. Triplett, eds. John Wiley \& Sons, New York.

Bureau of Meteorology. 2010. SA \& Adelaide Annual Climate Summary Archive. Online publication. Australian Government Bureau of Meteorology. http:// www.bom.gov.au/climate/current/annual/sa/archive/.

Campbell, C. L., and Noe, J. P. 1985. The spatial analysis of soilborne pathogens and root diseases. Annu. Rev. Phytopathol. 23:129-148.

Cooperman, C. J., Jenkins, S. F., and Averre, C. W. 1986. Overwintering and aerobiology of Cercospora asparagi in North Carolina. Plant Dis. 70: 392-394.

de Nazareno, N. R. X., Lipps, P. E., and Madden, L. V. 1992. Survival of Cercospora zeae-maydis in corn residue in Ohio. Plant Dis. 76:560-563.

de Nazareno, N. R. X., Madden, L. V., and Lipps, P. E. 1993. Characterization of gray leaf spot epidemics in maize. J. Plant Dis. Prot. 100:410-425.

Dyke, G. V., and Prew, R. D. 1983. Beans in crop rotations. Pages 263-269 in: The Faba Bean. P. D. Hebblethwaite, ed. Butterworths, London.

Groenewald, M., Groenewald, J. Z., Harrington, T. C., Abeln, C. A., and Crous, P. W. 2006. Mating type gene analysis in apparently asexual Cercospora species is suggestive of cryptic sex. Fungal Genet. Biol. 43:813-825.

Khan, J., del Rio, E., Nelson, R., Rivera-Varas, V., Secor, G. A., and Khan, M. F. R. 2008. Survival, dispersal, and primary infection site for Cercospora beticola in sugar beet. Plant Dis. 92:741-745.

Kilpatrick, R. A. 1956. Longevity of Cercospora kikuchii on soybean stems. (Abstr.) Phytopathology 46:58.

Kimber, R. B. E., and Paull, J. G. 2011. Identification and inheritance of resistance to Cercospora leaf spot (Cercospora zonata) in germplasm of faba beans (Vicia faba). Euphytica 177:419-429.

Lapaire, C. L., and Dunkle, L. D. 2003. Microcycle conidiation in Cercospora zeae-maydis. Phytopathology 93:193-199.

Latterell, F. M., and Rossi, A. E. 1983. Gray leaf spot of corn: A disease on the move. Plant Dis. 67:842-847.

Lawrence, J. S., and Meredith, D. S. 1970. Wind dispersal of conidia of Cercospora beticola. Phytopathology 60:1076-1078.

Madden, L. V., Hughes, G., and van den Bosch, F. 2007. The Study of Plant Disease Epidemics. American Phytopathological Society, St. Paul, MN.

McKay, M. B., and Pool, V. W. 1918. Field studies of Cercospora beticola. Phytopathology 8:119-136.

Meredith, D. S. 1973. Significance of spore release and dispersal mechanisms in plant disease epidemiology. Annu. Rev. Phytopathol. 11:313-342.

Muro, J., Irigoyen, I., Militino, A. F., and Lamsfus, C. 2001. Defoliation effects on sunflower yield reduction. Agron. J. 93:634-637.

Nagel, C. M. 1938. The longevity of Cercospora beticola in soil. Phytopathology 28:342-349.

Nutter, F. W., Jr., Martinson, C. A., Jenco, I., and Wegulo, S. N. 1994. Epidemiological studies concerning Cercospora zeae-maydis on maize. In: Proc. 32nd Congress South Afr. Soc. Plant Pathol. Christiana, South Africa.

Payne, G. A., and Waldron, J. K. 1983. Overwintering and spore release of Cercospora zeae-maydis in corn debris in North Carolina. Plant Dis. 67:87-89.

Proulx, R. A., and Naeve, S. L. 2009. Pod removal, shade and defoliation effects on soybean yield, protein, and oil. Agron. J. 101:971-978.

Ringer, C. E., and Grybauskas, A. P. 1995. Infection cycle components and disease progress of gray leaf spot of field corn. Plant Dis. 79:24-28.

Sumner, D. R., Doupnik, B., Jr., and Boosalis, M. G. 1981. Effects of reduced tillage and multiple cropping on plant disease. Annu. Rev. Phytopathol. 19: 167-187.

Vereijssen, J., Schneider, J. H. M., and Jeger, M. J. 2007. Epidemiology of Cercospora leaf spot on sugar beet: Modeling disease dynamics within and between individual plants. Phytopathology 97:1550-1557.

Vereijssen, J., Schneider, J. H. M., Stein, A., and Jeger, M. J. 2006. Spatial pattern of Cercospora leaf spot of sugar beet in fields in long- and recently-established areas. Eur. J. Plant Pathol. 116:187-198.

Walker, J. C. 1952. Diseases of Vegetable Crops. McGraw-Hill Book Company, New York

Wallen, V. R., and Galway, D. A. 1977. Studies on the biology and control of Ascochyta fabae on faba bean. Can. Plant Dis. Surv. 57:31-35.

Ward, J. M., Stromberg, E. L., Nowell, D. C., and Nutter, F. W. 1999. Grey leaf spot: A disease of global importance in maize production. Plant Dis. 83: 884-895.

Williams, M. A. J. 1987. Cercospora zonata. CMI Descriptions of Pathogenic Fungi and Bacteria No. 939. CAB International, Dordrecht, The Netherlands.

Windels, C. E., Lamey, H. A., Hilde, D., Widner, J., and Knudsen, T. 1998. A Cercospora leaf spot model for sugar beet. Plant Dis. 82:716-726.

Woodward, R. C. 1932. Cercospora fabae Fautrey, on field beans. Trans. Br. Mycol. Soc. 17:195, IN7-202.

Yu, T. F. 1947. Cercospora leaf spot of broad bean in China. Phytopathology 37: 174-179.

Zhang, J. X., Fernando, W. G. D., and Xue, A. G. 2004. Temporal and spatial dynamics of Mycosphaerella blight (Mycosphaerella pinodes) in field pea. Can. J. Plant Pathol. 26:522-532. 